This item was submitted to Loughborough's Research Repository by the author.

Items in Figshare are protected by copyright, with all rights reserved, unless otherwise indicated.

\title{
The role of highly skilled migrants in the process of inter-firm knowledge transfer across borders
}

PLEASE CITE THE PUBLISHED VERSION

http://dx.doi.org/10.1016/j.jwb.2014.01.006

PUBLISHER

(C) Elsevier

VERSION

AM (Accepted Manuscript)

PUBLISHER STATEMENT

This work is made available according to the conditions of the Creative Commons Attribution-NonCommercialNoDerivatives 4.0 International (CC BY-NC-ND 4.0) licence. Full details of this licence are available at: https://creativecommons.org/licenses/by-nc-nd/4.0/

\section{LICENCE}

CC BY-NC-ND 4.0

\section{REPOSITORY RECORD}

Liu, Xiaohui, Lan Gao, Jiangyong Lu, and Yingqi Wei. 2014. "The Role of Highly Skilled Migrants in the Process of Inter-firm Knowledge Transfer Across Borders". Loughborough University. https://hdl.handle.net/2134/14681. 
The role of highly skilled migrants in the process of inter-firm knowledge

transfer across borders

\author{
Xiaohui Liu \\ School of Business and Economics \\ Loughborough University \\ Leicestershire LE11 3TU \\ U.K. \\ Email: X.Liu2@lboro.ac.uk \\ Lan Gao \\ School of Business and Economics \\ Loughborough University \\ Leicestershire LE11 3TU \\ U.K. \\ Email: L.Gao@lboro.ac.uk \\ Jiangyong Lu* \\ Department of Strategic Management \\ Guanghua School of Management \\ Peking University \\ Beijing, China, 100871 \\ Tel: +86(0)1062767406 \\ Email: lujiangyong@gsm.pku.edu.cn \\ Yingqi Wei \\ Leeds University Business School \\ University of Leeds \\ Leeds LS2 9JT \\ U.K. \\ Email: y.wei@leeds.ac.uk
}

* Corresponding Author: Jiangyong Lu 


\begin{abstract}
Drawing on multiple case studies of Chinese highly skilled migrants working in the UK, we adopt an integrated approach that combines the contextualized explanation and processual approach to examine the role of individuals with a bilingual-bicultural background in the process of inter-firm international knowledge transfer (IKT). The findings reveal that the process is language and cultural dependent. Possessed with bilingual and bicultural competence, highly skilled migrants play a vital role at each stage of the knowledge transfer process between firms from their country-of-origin and from their adopted country, including identifying potential key contacts, relationship establishment and knowledge exchanges. The research advances existing IKT literature by bridging the analysis between a firm-level and individual-level of knowledge flows across borders, and by recognizing the impact of highly skilled migrants.
\end{abstract}

\title{
Keywords:
}

Bilingual skills, Bicultural background, Highly skilled migrants, Knowledge transfer process, Inter-firm international knowledge transfer. 


\section{Introduction}

The impact of language and cultural differences on international knowledge transfer (IKT) is a subject of emerging interest (e.g. Buckley, Carter, Clegg, \& Tan, 2005; Makela, Kalla \& Piekkari, 2007; Piekkari, 2006; Welch \& Welch, 2008). Previous studies have shown that language and culture exert a broad array of influences on IKT in such aspects as cost, transfer medium, teams, social networks, trust, staff movements and motivations (Welch \& Welch, 2008) and have enhanced our understanding of the role of language and culture in IKT. However, these studies have mainly focused on the extent of IKT and have treated IKT as a snapshot involving transmission and reception. A separate stream of knowledge transfer (KT) research has recognized that successful KT involves multiple stages and is much more than a one way, linear diffusion of knowledge within or between organizations (Duanmu \& Fai, 2007; Pérez-Nordtvedt, Kedia, Datta, \& Rasheed, 2008; Szulanski, 2000). There are various difficulties and challenges involved in any KT process, including the willingness to transfer and the attractiveness of the source, the lack of absorptive capacity and learning intent by the recipient, the quality of the relationship and causal ambiguity. Nevertheless, most studies in this camp take language and cultural contexts as given and seldom incorporate these contexts into the KT process. This represents an important research gap.

Related to existing research on inter-firm IKT, a significant increase in international immigration has become a major aspect of the globalization process (Docquier \& Rapoport, 2011). The number of international migrants increased from 75 million in 1960 to 214 million in 2010 (United Nations, 2010). International migrants contribute to the culturally diverse workforce with increasing numbers of individuals who have internalized more than one culture (Brannen \& Thomas, 2010). Among these migrants, highly skilled migrants ${ }^{1}$,

\footnotetext{
${ }^{1}$ Highly skilled migrants refer to people who have received tertiary education and hold master or doctoral degrees (World Migration, 2008).
} 
often educated in the West and working outside their country-of-origin, are of particular interest to IKT research as they occupy the middle ground between their country-of-origin and the adopted country.

Recent research in cross-cultural management extends the study of biculturalism to the workplace by recognizing the importance of bilingual-bicultural individuals in organizations, and provides insights into the heterogeneity of the workforce (Brannen \& Thomas, 2010; Fitzsimmons, 2013; Hong, 2010). However, these studies pay little attention to inter-firm IKT, and hence the way in which individuals with a bilingual-bicultural background affect inter-firm IKT has been under explored. Few studies have examined interfirm IKT at an individual level by explicitly investigating the relationship between the heterogeneity of individuals and IKT within the context of language and culture. There is a missing link between the KT process and the characteristics of individuals.

To address these research gaps, this study takes the first step towards delineating the process of inter-firm IKT by taking account of the impact of language and cultural contexts, and the role of highly skilled migrants. Specifically, we aim to investigate two related research questions. What is the process of inter-firm IKT within the bilingual and bicultural context? How do highly skilled migrants with a bilingual-bicultural background affect the IKT process? In other words, we intend to establish how highly skilled migrants affect each stage and the evolution of the IKT process in a bilingual-bicultural setting.

Recognizing the increasing heterogeneity of the workplace within the language and cultural context, we make several contributions to the literature. First, we adopt an integrated approach which combines the contextualized explanation (Welch et al., 2011) and processual approach (Abbott, 1995; Van de Ven, 2007). In so doing, our study moves away from a simplistic way of treating IKT as an outcome, which is often the feature of existing studies based on quantitative techniques (Blalock \& Simon, 2009; Filatotchev et al., 2011; Gong \& 
Girma, 2008; Görg \& Strobl, 2005; Tian 2007), to a contextualized perspective by taking into account the language and cultural contexts. The findings help provide new insights into IKT across language and cultural boundaries and broaden our understanding of the complexity associated with the dynamic process of inter-firm IKT.

Second, we examine the distinct role of highly skilled migrants in the IKT process and highlight the importance of migrants' bilingual and bicultural competence in identifying key contacts, building relationships, and facilitating knowledge dispatch and absorption in knowledge exchanges between the source and recipient of knowledge. To date, research on the IKT process has focused more on the organizational level rather than the individual level, despite the recognition of individuals as key players in the IKT process (Brannen \& Thomas, 2010; Welch \& Welch, 2008). Highly skilled migrants are not mere automatons reacting to opportunities and challenges in IKT; they can utilize their bilingual and bicultural competence to consciously make informed decisions. As a result, they play a crucial role in affecting the IKT process. Through focusing on highly skilled migrants, our study helps advance knowledge on how the characteristics of individuals contribute to the efficiency and effectiveness of inter-firm IKT, and broadens the IKT literature by recognizing workforce heterogeneity.

\section{Literature Review}

\subsection{The Process of Inter-firm IKT}

KT is commonly defined as activities and processes by which knowledge is deliberately moved across different units within an organization (intra-firm) or across organizational boundaries (inter-firm) (Argote, 1999). Knowledge flows are neither costless nor instantaneous, and KT involves a process comprising a recursive sequence with feedback loops (Pérez-Nordtvedt et al., 2008; Szulanski, 2000). The concept of process adopted in this 
study is defined as a sequence of events or activities that describe how things change over time (Abbott, 1995; Van de Ven, 2007). The processual approach takes a dynamic perspective to conceptualize process, involving the identification of the conditions of movement from one stage to the next (Monge, 1990), and helps provide a constructive way to take account of nuances in KT (Szulanski, 2000). Hence, it can be distinguished from a result, event or variance approach (Langley, 2007; Pettigrew, 1997) which mainly examines the benefits of KT and obscures the difficulties and challenges associated with KT.

Several studies on the IKT process examine how the characteristics of knowledge, the attributes of source and recipient firms, the networks and the relationship quality affect the efficiency and effectiveness of KT (Duanmu \& Fai, 2007; Gupta \& Govindarajan; 2000; Pérez-Nordtvedt et al., 2008; Szulanski, 1996; 2000). Szulanski (2000) suggests that there are four phases in the KT process: initiation (searching new knowledge), implementation (learning and preparing for KT), ramp-up (practicing the acquired knowledge) and integration. He finds that the reliability of sources affects the opportunity for KT in the early stages, whereas the recipient's ability to absorb knowledge determines the degree of difficulty during the implementation phases. The characteristics of the knowledge, such as 'causal ambiguity', represent barriers to KT throughout the process. Duanmu and Fai (2007) study IKT between MNCs and local suppliers in China and derive a three-stage pathway. Their findings show that the quality of the relationship and the level of trust at each stage determine whether simple or more sophisticated technological knowledge is transferred. Pérez-Nordtvedt et al. (2008) show that knowledge characteristics, recipient learning intent, source attractiveness, and relationship quality affect the effectiveness and efficiency of IKT. Extending this line of research, we treat inter-firm IKT as a dynamic process and explicitly examine the distinctive role of the language and cultural context in the process of IKT. 


\subsection{The Language and Cultural Context and the Process of Inter-firm IKT}

While the extent literature has recognized the importance of language and culture in the KT process (Kogut \& Zander, 1992; Welch \& Welch, 2008; Welch, Welch \& Piekkari, 2005), the attention largely focuses on intra-firm IKT with a few exceptions. Fai and Piekkari (2003) examine the impact of language on IKT and highlight that language is multi-tiered, subtle and complex, which either impedes or facilitates IKT. Buckley et al. (2005) investigate the role of language in facilitating KT in Sino-foreign joint ventures and emphasize that social knowledge is important in the successful articulation of the transferred knowledge. They show that speaking the same language is insufficient to ensure successful KT without shared social knowledge. Thus, language should not be separated from the cultural context in studying IKT (Peltokorpi, 2010; Peltokorpi \& Vaara, 2012). Several scholars (e.g. Brannen, 2004; Thomas, 2003; Tietze, 2008) have further developed the contextualization perspective which theorizes language affecting the degree of success in the transfer of knowledge, processes and practices into culturally different context. This perspective provides new insights into delineating the process of IKT in the context of languages and culture.

Our review of existing literature shows that the impact of language and culture in different phases of inter-firm IKT has received little systematic attention (Easterby-Smith, Lyles \& Tsang, 2008; Van Wijk, Jansen \& Lyles, 2008). Language and cultural differences represent particular challenges in the inter-firm IKT process because it involves parties with no shared organizational identity nor a commonly used corporate language, no established process and formalized structures to fall back on and potentially conflicting interests. These factors further complicate the process of IKT. We delineate the process of inter-firm IKT by explicitly taking into account the context of different languages and cultures.

\subsection{Individuals with a Bilingual-Bicultural Background and the Process of Inter-firm IKT}


Individuals embedded in the bilingual and bicultural context (i.e. bilingualbiculturals) have increasingly become the focus of attention in different disciplines (Brannen \& Thomas, 2010; Hong et al., 2000). Psychology research has placed a great emphasis on the antecedents of biculturalism and the effects of biculturalism on individuals (see Brannen \& Thomas (2010) for a detailed review). Hong et al. (2003) and Hong et al. (2000) propose the concept of cultural frame switching (CFS) which refers to a bicultural's ability to move between two cultural meaning systems. By internalizing and switching between cultural schemas, biculturals have more complex cultural representations and greater integrative complexity than monoculturals (Tadmor \& Tetlock, 2006; Tadmor, Tetlock \& Peng, 2009). Cross-cultural management research considers adaptability and boundary spanning as major advantages of individuals with a bicultural background (Friedman \& Liu, 2009). Hong (2010) further enriches the concept of bicultural competence by combining CFS and cultural metacognition. Cultural metgcognition refers to knowledge of and control over one's thinking and learning activities during cross-cultural interactions (Thomas et al., 2008). Individuals with a bicultural background tend to be associated with a higher level of cultural metacognition than those with a monocultural background (Brannen, Garcia \& Thomas, 2009). Individuals who have internalized two cultures often possess cultural knowledge and cross-cultural communication ability, as well as the ability to switch between cultural frames and apply cultural metacognition during cross-cultural interactions. As such, individuals who are embedded in two cultures are able to recognize cultural differences and react accordingly to give a positive impression in cross-cultural contexts (Hong, 2010).

Bilingual-biculturals can draw on dual language and cultural knowledge and naturally switch back and forth between languages and culture-based models. They are regarded as effective communicators across cultural contexts (Bell \& Harrison, 1996; Fontaine \& Richardson, 2003). Highly skilled migrants who have been exposed to the bilingual-bicultural 
context may have developed the information and interpersonal and action skills needed for successful IKT (Brannen, Garcia \& Thomas, 2009) as people engaged in IKT need to correctly understand and interpret the culture of both sending and receiving parties (Brannen, 2004). These migrants may play a vital role in bridging or mediating the source and recipient of knowledge in the process of IKT.

While the broad literature of IKT mainly focuses on an organization level as a unit of analysis, several studies recognize the role of individuals within MNCs and find that expatriates with language skills are powerful communication facilitators and act as language nodes (Harzing et al., 2011; Harzing \& Feely, 2008; Vaara et al., 2005). These studies briefly mention employees with a bicultural/bilingual background as 'bridge individuals' in IKT; however, there is a lack of systematic studies on how these individuals influence IKT. Migrants with bilingual and bicultural competencies are different from expatriates. Expatriates act as a means of control and knowledge transfer within an MNC and are often selected on the basis of technical competence and experience in the home country (Tung, 1987). They may lack the ability to overcome language and cultural barriers in host countries, which can result in expatriate failure (Goodall \& Roberts, 2003; Paik \& Sohn, 2004; Osland, 2000). Migrants, on the other hand, as a unique group occupying the middle ground, may be more efficient and effective in facilitating KT between their country-of-origin and their adopted country. This unique position has not been explored before. This is surprising, given the significant increase in international migration by highly skilled people working outside their home country and contributing to the diversity of the employee demographic.

\section{Research Design}

We employ the contextualized explanation and processual case study approach. The former emphasizes the importance of context in explaining the causal mechanisms and 
pathways, and establishes causes-of-effects explanations by integrating contexts into discussions (Welch et al., 2011). By contrast, traditional inductive case study research establishes relationships between variables free from the context (Eisenhardt, 1989; Yin, 2009). The latter from the organizational behavior field combines the strength of deductive reasoning and inductive pattern recognition (Duanmu \& Fai, 2007). The combination of both approaches allows us to generate knowledge not only of the outcomes but also of why and how outcomes are shaped by processes (Pettigrew, 1997).

Based on the literature and pilot interviews with highly skilled Chinese migrants involved in IKT between the UK companies they work for and Chinese firms, we constructed a set of questions and used the semi-structured interview technique which allows new patterns that were not identified in previous research to emerge. The interviews focused on cases where IKT was part or the sole purpose of business deals between independent British and Chinese firms. For example, a British company provided technical training to Chinese counterparts regarding a new product or technology, or a British company transferred a package of technical know-how to a Chinese company. In addition to the flows of technical know-how from the British side to Chinese companies, we discovered in our pilot interviews that British companies often proactively seek knowledge of local competitive dynamics from their Chinese counterparts. Therefore, in the interviews, we focused on the role of highly skilled Chinese migrants in mutual knowledge transfer between their British companies and Chinese counterparts.

A multiple case study method provides us the opportunity for a comparison across cases (Yin, 2009). To identify potential interviewees, we contacted the Chinese Embassy in the UK and a few Chinese associations in the UK, including the China-UK Business Association (CCCB), the Chinese Economic Association (CEAUK), and the Association of Chinese Engineers (ACEUK) and obtained a list of Chinese migrants who were working in 
the UK. To increase the comparability among the cases, we narrowed down the sample to IT or pharmaceutical industries because of the information- and knowledge-intensive nature of these industries. We contacted potential interviewees by email, explaining the aim and scope of our research and offered to provide a practitioner-oriented report to encourage participation and received 30 positive responses. We then confirmed their suitability and availability via telephone and excluded those who were not involved in business activities in China and those who only worked for Chinese subsidiaries. Thus, our first sample consists of 14 interviewees who were working for UK companies with business links to Chinese firms, where both firms are independent of each other.

All interviewees completed part (the highest degree) or all of their higher education in the UK and had been in the country for at least six years, including a minimum of three years work experience (by the time of the first round interview). They have been extensively exposed to the English language and British culture while maintaining their Chinese identity and subscribing to core Chinese values.

Among all interviewees, three (Interviewees C, F and I) were recruited with the explicit purpose of supporting their company's businesses in China or East Asia. All others were appointed to positions that initially did not involve IKT. However, gradually, these interviewees became engaged in their firms' business activities in China because of their technical or bilingual skills. Their firms started to realize the benefits of using Chinese migrants when engaging in IKT with Chinese counterparts, and the migrants themselves were aware of their advantages in facilitating the process compared to their British colleagues. Consequently, both the Chinese migrants and their employers actively exploited these advantages in the IKT process. Some of them, such as Interviewees A, E, F and L, became senior managers in charge of their firms' business activities in China, including IKT.

At the end of interviewing Chinese migrants in the UK, we asked for their help in 
order to get introductions to their Chinese counterparts so that they could also participate in our research. A total of 11 interviewees provided their Chinese counterparts' contact information and these people were subsequently interviewed. In total, we conducted 25 interviews. All interviews were face-to-face and used Mandarin, the interviewee's home tongue, in order to create a comfortable environment and encourage information sharing. Each interview lasted between one and a half and two hours. Under a guarantee of anonymity, all were digitally recorded and transcribed within 24 hours of the interviews to minimize information loss. Tables 1 and 2 list information on the interviewees and dates when the interviews were conducted.

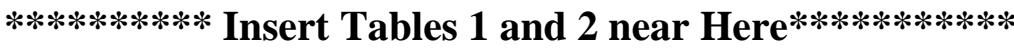

We approached the interview transcripts with a minimal conceptual framework derived from the literatures on the IKT process, the language and cultural context and the role of individuals with a bilingual and bicultural background in IKT. Following the guidelines suggested by Glaser and Strauss (1967) and Miles and Huberman (1984), data analysis involved constant comparison between the data and emerging theoretical constructs. We started by analyzing each interview transcript to generate first order codes via open coding. The codes were iteratively adapted, then integrated in order to form provisional theoretical categories within each case. Within-case analysis was followed by cross-case analysis and this generated the preliminary theoretical categories as several provisional categories were confirmed appropriate, while others needed to be modified.

To increase the validity of the coding, two of the authors conducted data analysis independently. This process proved effective in developing understanding of the research questions as there was a high degree of consistency between the two analyses. In the open coding stage, if a quote was coded into different theoretical categories, checks were undertaken to ensure correct understanding within the context. The quote was re-coded to the 
appropriate category where necessary. If the quote itself resulted in alternative interpretations, the relevant interviewee was contacted for clarification. On a few occasions where one category (such as trust) was identified by one author but not the other, discussion revealed that the category was labeled as a sub-category by the other. In such cases, the authors drew on insights from previous literature and had open discussions about the data and emerging categories in order to reach a final decision. This validation process brought a consensus on the final categories. Subsequently, all interview transcripts were reviewed against the final categories. These theoretical categories, and their relationships with one another, were examined in cross-case analysis for patterns and processes in an attempt to understand how different categories fit together in a coherent manner.

Figure 1 provides an overview of our data structure. We adopted a three-step process to analyse the data (Gioia et al., 2013). In the first-order analysis, we identified 16 codes using the interviewees' own terms. In the second-order analysis, we identified six theoretical themes. In the third-order analysis, we classified these categories into three stages of the inter-firm IKT process in the presence of highly skilled migrants: contact identification, relationship establishment and knowledge exchanges.

$* * * * * * * * * *$ Insert Figure 1 near Here $* * * * * * * * * * *$

\section{Findings}

This section presents details of our findings, including the delineated stages of the inter-firm IKT process, the language and cultural context and the role of Chinese migrants in each stage. The inter-firm IKT process is a combination of both structured and unstructured process of KT between two independent firms within different language and cultural contexts. The evidence reveals that the inter-firm IKT process is dynamic involving recursive progression with a feedback loop from contact identification, relationship establishment to 
knowledge exchanges. The process starts long before the communication to exchange knowledge between the source and the recipient. In the first stage, contact identification, a firm needs to identify the IKT partner. This stage involves searching for the partner firm and identifying the key contacts within and outside the firm who play an indispensable role in assisting both parties in the IKT to move on to the next stage of relationship establishment.

Following contact identification, the parties will start establishing a quality relationship. Without the ability to develop and maintain a quality relationship between potential partners, it is impossible for IKT to be successful. The quality of established relationships has a direct impact on the amount and quality of knowledge transferred. If one party is unable to build a quality relationship with its counterpart, or it has developed a relationship with an unsuitable contact, it needs to move back to the first stage and find the right contacts.

Armed with an established quality relationship, firms enter into the third stage, knowledge exchanges, which consists of two sub-stages, knowledge dispatch from the source and knowledge absorption from the perspective of the recipient. These two sub-stages are interrelated and represent an interactive process with intensive knowledge flows from the source to the recipient initially, then feedback from the recipient to the source for clarification. The stage of knowledge exchanges is completed when receivers accurately absorb the knowledge delivered by senders. This interpretation includes both the literate meaning and the underlying messages which need to be decoded by drawing on cultural knowledge. Language and cultural differences often cause a breakdown at this stage if senders and receivers lack the necessary skills in accurately sending and absorbing the transferred knowledge, respectively. The source may need to recode the knowledge for improved understanding and effective absorption by the recipient. Issues raised in this stage may also lead the source or the recipient to going back to the contact identification stage or the 
relationship establishment stage. Below we present findings on the dynamic process of IKT in language and cultural contexts and the role of Chinese migrants in each stage, and the evolution of the process.

\subsection{Contact Identification}

The initial stage of the inter-firm IKT process is to identify potential knowledge exchange counterparts. This includes identifying the firm, but most importantly, the individuals who hold the key for successful IKT, including decision-makers who determine whether the IKT will take place, and technicians who are directly involved in IKT as well as outside 'gate-keepers' who can influence the decision-making process of IKT.

In this digital era when the global market seems to be 'one click' away, it is not difficult to identify a potential firm. Internet or international exhibitions present British firms with opportunities to detect potential IKT counterparts in China. However, what is more difficult is to pinpoint the key individuals both within and outside the Chinese firm. British people may find it hard to understand the complexity of social relationships in China. Chinese migrants, on the other hand, can take advantage of their language and cultural competence to access information, and, therefore, identify the appropriate contacts for their British employers. This applies to both first-time relationships and existing business relationships. For first-time relationships, Chinese migrants can help build a good foundation for the IKT process by finding the right contacts. Because of their bilingual and bicultural competence, Chinese migrants can quickly gather background information about their Chinese counterparts and understand who is in charge. When there are existing business relationships between UK and Chinese firms, Chinese migrants can facilitate the efficiency and effectiveness of existing IKT projects. In many of our interviewed cases, Chinese migrants were assigned to existing projects because the projects had not gained ground. Often, 
they found that the reason was that the British side did not identify the right contacts who held the key for successful IKT. Because of the language and cultural advantage, Chinese migrants can more easily pinpoint what or who is causing problems.

"I can easily tell who is the boss and who is the technical person in our client's team, especially after a dinner or even just a chat over coffee. So I know who to talk to when I need to discuss a particular issue (relating to knowledge exchanges)." (Interviewee A)

Besides directly identifying key individuals in the Chinese firms, Chinese migrants can also pinpoint the 'gate-keepers' outside the firm, such as government officials or local influential figures who have a close relationship with the identified key contacts in the firm. Being introduced by a 'gate-keeper' to the key contacts can often lead to closeness between Chinese migrants and the contacts because the contacts perceive that getting to know Chinese migrants represents a favor to the 'gate-keeper' which will be repaid in the future.

"For my current project, I first contacted local trade promotion officials, and then had a dinner with them and our business partners together. The involvement of local government officials really made a difference in how our partners perceived us. It actually raised our status. Therefore, our partners took us and our project more seriously." (Interviewee D)

\subsection{Relationship Establishment}

"Identifying a potential business partner is not difficult in this digital era. The essential element (for smooth IKT) is to build and maintain a quality relationship with them." (Interviewee $M)$

Relationship establishment is considered by the interviewees another important stage determining the quality of inter-firm IKT. In China, successful KT often happens between people with strong ties or membership of in-groups (Davison, Ou \& Martinsons, 2013). 
Therefore, the ability to develop quality relationships with Chinese business counterparts is essential in successful IKT. Following Pérez-Nordtvedt et al. (2008), quality relationship refers to the extent to which the relationship between the recipient and the source is close, strong, and based on mutual trust (p. 722).

Chinese migrants know how to approach the people in charge of KT because of their understanding of, and familiarity with, the society and culture. Their ability to speak Chinese and their deep understanding of the Chinese culture enables them to quickly establish contacts with whom they can build a close business relationship and extended network, the foundation of knowledge exchange in the Chinese society. Neither the cultural background nor the language skill is dispensable in this process. The former enables Chinese migrants to know what is appropriate to say, while the latter ensures that they know how to express themselves. All of the interviewees shared the same view that their bilingual skills and understanding of the Chinese culture give them advantages in developing new relationships and maintaining existing ones in China compared with their native British colleagues. Interviewee D and L explicitly stated:

"For Chinese, a network can be built whenever it is needed, as long as you are ready to follow cultural norms in China."

"Of course it is easier for me to establish relationships in China. This goes back to the language and cultural advantages. I don't need an interpreter to sit beside me so communication will be more thorough. I don't need to worry about the possibility of saying something which could offend our business partners."

The quality of relationships established by Chinese migrants is further boosted by their ability to enter the trust circle and become an in-group member. In the Chinese culture, asking a person to share his/her knowledge is equivalent to asking for personal favors which are normally only shown to people who are part of a trusted network (Huang, Davison \& Gu, 
2011). The shared language and cultural background enable Chinese migrants to quickly become insiders. The 'ZIJIREN' (one of our own) concept was repeatedly mentioned by our interviewees. Foreigners and Chinese migrants, both of whom work for the same British company, are perceived very differently by their Chinese counterparts. Because of the collective characteristics embedded in Chinese culture, overseas Chinese, regardless of their current nationality, are all considered part of the greater Chinese family.

"Chinese people certainly treat me and my British colleagues differently. For me, I belong to the same group. I am an insider. They accept me as Chinese. For foreigners, well, foreigners are just foreigners. ...... I am 'ZIJIREN'., (Interviewee A)

Chinese migrants can build on the advantage of being 'ZIJIREN' to further develop the relationships with their Chinese counterparts in various informal circumstances, such as dinners and other social events, on top of formal meetings. Migrants are often invited to outof-office activities organized by their Chinese counterparts, who feel that it is easier to mingle with Chinese migrants than with foreigners because of the shared language and the perceived natural bond rooted in Chinese culture. Interviewee 3 said,

"We often invite them (Chinese migrants) to dinner or even a day trip over the weekend. It's natural. We have plenty to talk about. ...... It's more like meeting friends rather than a formal business partner......It is very rare to invite British people unless it is a formal business dinner. With foreigners, you just don't feel like you have much to talk about."

As part of the 'ZIJIREN' community, it is easier for Chinese migrants to ask their Chinese counterparts to share knowledge, with the mutual understanding/obligation that the Chinese counterparts will receive reciprocal treatment from the migrants in future. Migrants are expected to filter the knowledge and advise the Chinese counterparts regarding how much and which part of the knowledge should be transferred to the foreign company and, more importantly, how to effectively communicate with them. Therefore, migrants are not only 
serving the interests of their company, but also supporting the interests of their Chinese counterparts. This reciprocity makes it easier for Chinese migrants to facilitate KT because of their position occupying the middle ground (the filter place) and being able to switch between different contexts of languages and social interactions. Consequently, they serve the interests of both sides and overcome any lack of trust and understanding between the two parties. Interviewees A and E explained,

"Our partner did not want to discuss with my boss simply because he did not want to show his ignorance in front of the British in order to save face. But with me, he was much more relaxed. So we got to know exactly what we needed to do, while our partners got what they wanted as well as saving face."

"Every time I went to China with my boss, our Chinese counterparts treated us very well and were very polite and friendly...... However, all communication was with me rather than my boss. They wouldn't discuss the issues, especially problems, with foreigners. I then passed the information to my boss in a way that he could understand, as I had to protect the Chinese side. Then we can move on."

This reflects a deep rooted element in Chinese culture, 'face saving', which has a negative effect on Chinese people's knowledge sharing as they are afraid of making mistakes in public which would cause embarrassment and losing face (Huang et al., 2011). Relying on the close relationship, Chinese counterparts can expect Chinese migrants to give a reciprocal favor by helping them to save face in return for sharing knowledge. Without the active involvement of Chinese migrants, the KT process will be delayed or ineffective. British people are much less able to build the same quality relationships with their Chinese counterparts because of the language and cultural barriers, and thus the subsequent knowledge transferred is often limited and superficial in a given time.

"I inherited my current project from my (British) colleagues. They had worked on this 
for more than a year, but made VERY little progress. They simply could not get the Chinese side to open up because they could not become 'friends' with the Chinese." (Interviewee F)

"Knowledge transfer can still happen without Chinese migrants, but it would not be as thorough and effective. In (formal) meetings with foreigners, we only say what is absolutely necessary. It's strictly business." (Interviewee 2)

\subsection{Knowledge Exchanges: Dispatch (Source) and Absorption (Recipient)}

The final stage involves two interrelated sub-stages from the source and the recipient of knowledge. For the source, an established quality relationship leads to the knowledge dispatch stage, where the source codes the knowledge and passes it on to the recipient. For the recipient, once knowledge is received, they must make sense of it in order to absorb and integrate into their own system. Both the language and cultural competency of migrants are important for this final stage.

First, the knowledge exchange stage often involves translation because of the different languages used by the source and recipient. Senders need to encode the knowledge in a language that can be understood by the receiver, but is not necessarily their own language. Recipients need to interpret and understand the meaning embedded in the encoded knowledge in order to absorb it. This increases the complexity of the IKT process, especially when one side has low proficiency with the language used in communication. The language barrier can reduce the accuracy and volume of the knowledge package dispatched. Below is an example from Interview A:

"Many (Chinese) top managers normally do not speak English very well. They cannot communicate with Westerners without involving a translator who often lacks either technical knowledge or cultural understanding. However, with me, they do not have any communication problem." 
The beneficial effects provided by Chinese migrants apply to the exchange of explicit knowledge, which is often considered to be standardized and easily codified. However, many Chinese professionals in China have reasonable fluency with general English but find it difficult to cope with more subject-specific English, while British people often have a low level of proficiency in Chinese. Communication between them is often impossible, or less meaningful, without involving interpreters who often lack in-depth subject-specific and context-specific knowledge. In comparison, Chinese migrants can act as a bridge for both the source and the recipient given their bilingual-bicultural background. All interviewees explicitly stated that subject-specific knowledge could be exchanged more accurately and efficiently because of their bilingual skills.

"I was called in when they (British colleagues) were doing training for Chinese clients because our Chinese clients could not understand, especially engineering related technical terms......Now, I am the person in charge of delivering all training to Chinese clients in Chinese." (Interviewee B)

"I think that communication between me and my Chinese counterparts is easy, especially when talking about technical issues. Something that cannot be clearly understood in English can be easily explained in Chinese." (Interviewee J)

Furthermore, Chinese counterparts are reluctant to show their English language limitations in front of foreigners, in order to save 'face'. Even when the language is less of an issue, the Chinese counterparts are still unwilling to express their opinions to foreigners as they may feel that expressing a different opinion, or the way that they express that opinion, may cause offence. As a result, the Chinese counterparts are more willing to exchange knowledge with Chinese migrants since they can communicate in the same language and in the Chinese way. This is reflected in the statements of interviewees B and F.

“Because they don't understand how foreigners really think about the issue, they 
don't directly express their own thoughts. With me, the communication would be easier. After all, we have the same cultural background."

"My Chinese counterparts often prefer talking to me in private as they don't know how to communicate with Westerners and they feel embarrassed about their English level."

In addition, cultural elements which are needed to decode the knowledge package correctly are often not explicitly encoded in the package. Even when language is not an issue, misunderstandings can still occur due to the different cultural context. The evidence reveals that there is often an 'under-interpretation' at the British side and an 'over-interpretation' at the Chinese side. On the one hand, British often take the literal meaning of the message because they presume that Chinese people communicate in the same explicit way as themselves. However, in China, knowledge is very often embedded in the context of the message, and this makes it even more difficult for British people to understand. For example, opinions expressed by Chinese people at a lower position carry little weight in the final decision making. An agreement between these people and the British side may easily be overruled by their superiors. Therefore, "not only the 'Yes' notion is important, but the person who said it is sometimes more important" (Interviewee G). As a result, the British sides often find their effort in the IKT process is in vain if they interpret all messages literally without taking into account the context. While for Chinese migrants, who understand the hierarchical society of China, they know whose opinions should be considered seriously and often actively seek confirmation from higher-rank managers on the Chinese side.

On the other hand, the Chinese tend to over-interpret by asking themselves unnecessary questions: "Is there any underlying message that the British want to deliver? What do they really think about the issue?" (Interviewee 2). This is because the Chinese side may feel that they do not have the whole picture and they are unsure which elements are the most important, thus resulting in ineffectiveness in knowledge absorption. 
Our interviewees in China further stressed the point that the involvement of Chinese migrants helps to reduce the chance of misunderstanding. There are times when both sides speak in English but have a different understanding of what has been said because of the cultural difference. Chinese migrants help to spot potential collisions and make sure that both sides absorb the knowledge dispatched by the other side appropriately.

"We (the management team) neither speak very good English nor understand their (Western) culture very well. A Chinese migrant who really understands Western culture can make knowledge exchange smoother. So it won't be the situation where the two sides are talking their own 'language'." (Interviewee 4)

\section{Discussion}

The inter-firm IKT process is complex and context-dependent and involves individuals, groups and organizations (Argote, 1999; Simonin, 2004). In this study, we explicitly focus on the language and cultural context, and individuals who are specifically highly-skilled migrants with language and cultural competency. Drawing on the findings of the multiple case study in which British and Chinese firms transfer knowledge to each other with the assistance of Chinese migrants employed by the British firms, we develop a conceptual model that reveals the role of the language and cultural context in the process of inter-firm IKT and shows how migrants facilitate each stage of the process. As shown in Figure 2, inter-firm IKT is a dynamic, language- and culture-dependent process with three recursive stages. Each stage involves extensive interaction and communication between the source and recipient of knowledge. The interactive and dynamic nature of the IKT process implies that the source and recipient of knowledge move back and forth. When the two parties encounter language and cultural barriers or difficulties in one particular stage, they go back to an earlier stage to re-develop the IKT process. For example, under the circumstance 
when one party is unsatisfied with the third stage of the knowledge exchange, they may go back to either relationship establishment to enhance further the inter-organizational and interpersonal relationship or maybe even to the contact identification stage so as to find the right contacts to facilitate the process. It shows that the language and cultural contexts affect each stage and the evolution of the IKT process, and thus determine the efficiency and effectiveness of IKT. Migrants play a central role from the initial stage, contact identification, then the relationship establishment stage to the final stage, knowledge exchanges. As conceptualized in Figure 2, we will discuss in detail the process of IKT in the language and cultural context and the role of migrants in each stage and derive propositions accordingly.

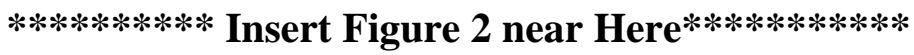

\subsection{Propositions}

The inter-firm IKT process starts with identifying potential KT counterparts. This stage may be invisible in the process of intra-firm KT (Szulanski, 2000) as parties involved all share the same organizational identity and a common understanding of where and from whom they can obtain knowledge, or they may be given information directly within the organization. However, the same does not apply to inter-firm KT. The first stage is crucial as it involves the mutual evaluation of the suitability of the source and the recipient and determines 'usefulness' and relevance of transferred knowledge (Lord \& Ranft, 2000; PérezNordtvedt et al., 2008; Simonin, 2004). The stage is influenced by both parties' language and cultural context. Given the large pool of potential knowledge sources, or the potential knowledge recipients at the firm level, and the even greater number of individuals in these organizations, language differences can inhibit effective communication and interaction in searching for the right partner. However, employing the same language between the source and the recipient does not make contact identification trouble free. Cultural dissimilarity can 
cause misunderstandings. Large language and cultural distance increases the difficulty associated with identifying the right contacts to deal with in the later stages of the IKT process. Furthermore, the language and cultural context influences the progression from contact identification to the following stage of relationship establishment.

Establishing quality relationships between parties involved in IKT lays the foundation for later knowledge exchanges. Like stage one, it may be less of an issue in intra-firm IKT as the headquarters can mandate knowledge transfer within an MNC. However, for inter-firm KT, although through the contact identification stage the source and the recipient establish their willingness to transfer knowledge, without proper relationship building they may lack the trust necessary to proceed to knowledge exchange. This is particularly important in highly collective societies, such as China, where networks or 'Guanxi' are the foundation of social activities. A similar stage has been identified in Duanmu and Fai (2007) and Millington, Eberhardt and Wilkinson (2006). They highlight the importance of social relationships such as Guanxi in the IKT between Western firms and Chinese local suppliers. This is echoed by Buckley, Clegg and Tan (2006) who also highlight the importance of establishing good interpartner relationships in IKT through removing cultural barriers. If a quality relationship cannot be formed, firms have to move back to the contact identification stage and restart the whole process.

Once a quality relationship has been established, the knowledge exchange phase commences. This stage begins with the sub-stage of knowledge dispatch, i.e. the source conveys knowledge to the recipient. When knowledge reaches the recipient, this is not the end of the successful KT as the recipient may not fully absorb the knowledge due to the potential for misunderstanding and/or misinterpretation. The recipient may ask for further clarification or complementary information/knowledge in order to accurately absorb the knowledge transferred. Knowledge dispatch and knowledge absorption together consist of a 
spiral process and reach the end when both parties are satisfied with the final outcome. The efficacy of dispatching and absorbing knowledge relies on the language and cultural aspect of the parties involved. Dissimilarity in language and culture may lead to inefficiency and cost the source and recipient a significant amount of time and resources because of the inadequate comprehension of the extent of knowledge that needs to be encoded, detailed and transferred (Welch \& Welch, 2008). Our findings not only confirm that language and cultural barriers may lead to misunderstandings and increased costs (Reagans \& McEvily, 2003; Buckley, et al., 2005), but also show that both explicit and tacit knowledge needs to be interpreted within the cultural context.

The knowledge absorption stage has been identified in prior research (Duanmu \& Fai, 2007; Pérez-Nordtvedt et al., 2008), but existing studies take the language and cultural context as given and overly emphasize the properties of knowledge and the technical barriers in the absorption stage (Szulanski, 2000). While Welch and Welch (2008) offered a conceptualized study of the role of language in IKT within MNCs and Buckley et al. (2006) noted the impact of language and social and cultural knowledge on IKT between Sino-foreign joint ventures in China, none of them has examined the process of IKT. Prior research has proposed that modest cognitive distance between organizations involved in knowledge transfer fosters learning (Foss, 1999; Nooteboom et al., 2007). However, the cognitive distance is measured using differences in technological knowledge between firms without taking the cultural context into account. Our findings complement prior studies. Language differences and cultural distance represent cognitive barriers to inter-firm IKT and should not be taken as given when dealing with IKT. Taken together, our findings show that the process of IKT involves extensive interactions between sources and recipients at each stage within the language and cultural context. The dynamic interactions determine the extent to which successful IKT can be achieved. Hence, 
Proposition 1: The process of inter-firm IKT is dynamic and involves three main stages, namely contact identification, relationship establishment and knowledge exchanges that include knowledge dispatch and knowledge absorption. The impact of the language and cultural context on knowledge transfer is highly visible at each stage as well as the evolution of the inter-firm IKT process.

The role of individuals with bilingual and bicultural background in organizations is an emerging research field (Brannen \& Thomas, 2010). These individuals often speak two languages and identify with the corresponding cultures and, therefore, are aligned with two sets of socially constructed cognitive systems that contain values, attitudes, beliefs and behavioral assumptions. They can utilize their language and cultural competence and act as bridges among organizations, linking culturally different contexts and facilitating knowledge flows (Brannen \& Thomas, 2010; Fitzsimmons, 2013).

Our findings explicitly show how Chinese migrants with bilingual and bicultural competences contribute to IKT and are valuable facilitators at each stage of the evolution of the IKT process. Migrants have advantages in identifying and accessing knowledge sources/recipients in their country of origin. Their CFS ability helps in effectively switching between British and Chinese practices to fit the circumstances (Hong et al., 2000). In particular, their bilingual and bicultural competences are able to increase the efficiency and effectiveness when identifying suitable contacts who hold the key to successful knowledge transfer. Migrants have the ability to quickly gather the necessary information and navigate the complexity of Chinese social relationships, thus helping identify the key contacts who could determine whether knowledge exchange is feasible. Our findings reveal that the breakdown of KT between both sides is often caused by the British side failing to identify the 
right contacts in its Chinese counterparts as they are puzzled by the complex hierarchy and inter-person relationships within the Chinese company. With their ability to interact with their Chinese counterpart, migrants are able to overcome this identification barrier at the very beginning of the IKT process, thus building a solid foundation for IKT.

In addition to identifying the key contact for IKT within their Chinese counterparts directly, migrants can also seek to connect with the key contact through indirect links outside Chinese companies, such as government officials who act as gatekeepers, to help them gain access to the direct key contact. Migrants can easily get their Chinese counterparts' attention if they can involve government officials (Buckley et al. 2006). Chinese firms usually give higher priority to projects that the government is interested in as they want to show the government that they are taking its opinions seriously, and also in the hope that they will gain reciprocal favors at a later stage. The findings indicate that Chinese migrants have an advantage over expatriates as both language and cultural competences enable them to become insiders. The ability of migrants to both pinpoint and contact gatekeepers makes a significant contribution to successful IKT. Hence:

Proposition 2: Migrants with bilingual and bicultural competencies are more effective in identifying key contacts directly from the KT partner side and seeking to connect the key contacts through external gatekeepers.

Sharing cultural identity and common language enables migrants to facilitate further development of quality relationships between IKT participants. Establishing high quality relationships is particularly important in inter-firm IKT as prior research has found that KT takes place only when the sources of knowledge are willing to transfer information. This willingness is influenced by the relationship quality (Gupta \& Govindarajan, 2000; Pérez- 
Nordtvedt et al., 2008; Szulanski, 1996). A quality relationship can lead to a high degree of trust and understanding because of the perception of the low level of the other's opportunistic behavior (Wang, Tong \& Koh, 2004). The shared language and cultural background symbolizes the similarity and belongingness of the same group (Hogg \& Terry, 2000). Such language and cultural advantages enable migrants to facilitate the volume and the speed of IKT (Pérez-Nordtvedt et al., 2008).

Compared to their British colleagues, migrants generally find it easier and quicker to be accepted into local Chinese networks because of their ability to identify with Chinese cultural schema. They are accepted as part of the Chinese community and perceived as 'ZIJIREN' regardless of their current nationality, while their British colleagues are perceived as foreigners from another country and outsiders from another company, and therefore are subject to the 'liability of foreignness' and 'liability of outsiderness'. Chinese counterparts expect migrants to understand the 'reciprocity' culture of China and behave accordingly. Therefore, migrants can easily receive initial trust from their Chinese counterparts with reciprocal conditions. By fulfilling their side of reciprocal favors, migrants are able to build quality relationships with their Chinese counterparts. This confirms prior findings that the collectivistic Chinese culture tends to draw sharper distinctions between in-group and outgroup affiliations (Jonsen et al., 2011). This has implications for how people in this cultural context perceive outsiders and how much information they are willing to exchange with outsiders, and hence the importance of bicultural-bilinguals in bridging the gap across cultural boundaries.

The knowledge transfer literature has recognized the importance of networks which serve as an informational conduit and facilitate knowledge transfer (Inkpen \& Tsang, 2005; Pérez-Nordtvedt et al., 2008). However, much remains to be uncovered regarding the mechanisms underlying the initial formation of a network and relationship. Our findings not 
only reassert the importance of language and culture for $\mathrm{KT}$, as found in prior literature (Buckley et al., 2005; Welch \& Welch, 2008), but also emphasize the importance of bilinguals and biculturals in developing the relationships needed for KT. Although the importance of trust building is well documented in existing literature on IKT (Buckley et al., 2006; Huang et al., 2011), the question of who can help develop trust and smooth the process of IKT remains largely under-explored. We offer case evidence pointing out the role of migrants. Hence,

Proposition 3: Migrants with bilingual and bicultural competence help mitigate the negative impact of language and cultural barriers, and enhance the willingness to exchange knowledge through developing quality relationships between participants of inter-firm IKT.

The perception of the knowledge transferred may differ from the actual amount of knowledge transferred due to language and cultural barriers. However, migrants with bilingual and bicultural competence are able to overcome such barriers and ensure the effectiveness of knowledge transfer. IKT requires cross-cultural communication where the use of language is crucial (Welch \& Welch, 2008). When people do not speak the same language, important information may be lost or distorted in the process of translation. Dispatched knowledge can also become ambiguous or difficult to understand for people who do not share the same language. People from different cultural backgrounds may interpret the same message differently based on knowledge drawn from their own cultural background (Henderson, 2005; Roberts, 2000). A lack of understanding of the relevant cultural context can result in incorrect decoding of the knowledge and can lead to ineffectiveness in absorbing knowledge. Embedded in the bicultural contexts of their country-of-origin and host country, migrants are able to correctly interpret the knowledge and help both sides to absorb the 
knowledge conveyed.

The evidence reveals that the low English language proficiency of Chinese KT partners constrains effective communication and makes them less able to transfer knowledge to or absorb knowledge from their British counterparts. The latter also rarely have reasonable proficiency in Chinese. This language gap is exacerbated by differences in the cultural context. Embedded in Chinese culture, Chinese people are worried about losing face if they say something incorrect or inappropriate in a foreign language. Face (Mianzi) is a special term in Chinese culture and represents the social position and prestige gained from the successful performance of specific social roles that are well recognized by other members in the society (Chen \& Starosta, 1998). It has particular salience for the Chinese as a person's face is his/her pride and dignity. Deeply rooted in the Chinese society, and prevalent in social interaction, saving face creates a social pressure and expectation which influences Chinese people to be less openly assertive (Kirkbride, Tang \& Westwood, 1991). Hence, such a cultural characteristic, plus language barriers, reduces the amount of knowledge dispatched from Chinese firms to foreign firms. However, with the involvement of migrants, Chinese KT partners can ease the concern of losing face associated with speaking a foreign language.

Our findings further disclose that explicit technology has a tacit dimension which can inhibit KT in a different language and cultural setting (Brown \& Duguid, 2001). This differs from the conventional assertion that explicit knowledge can be codified into standard technical terms and easily adopted across cultural contexts (Argote, McEvily \& Reagans, 2003). This assumes consistency between coding explicit knowledge by the source and decoding it by the recipient using a language that can be understood by both parties. However, if both source and recipient do not share a common language, how to communicate knowledge that could promote appropriate interpretation and synthesis between firms may be a problem. Even when they do share a common language, they sometimes use different 
'technical' languages which are embedded in different cultural contexts (Duanmu \& Fai, 2007). In this sense, any knowledge is more or less 'sticky' and tacit when putting the language and cultural context into knowledge exchange. Our findings indicate that language as a communication channel, and culture as an underlying factor, are crucial to the quality and efficacy of KT. Migrants with bilingual and bicultural competence are able to bridge language and cultural gaps and increase the accuracy and efficacy of IKT. Specifically, bilingual and bicultural competence promotes mutual understanding, represents crucial bonding mechanisms and enables migrants to re-contextualize the exchanged knowledge (Brannen, 2004), thus contributing to a smooth, less costly and less-time consuming IKT process.

While existing studies recognize that factors, such as absorptive capacity and technological gaps, as well as prior knowledge transfer experience, affect KT (Castellani \& Zanfei, 2003; Liu \& Buck, 2007; Nooteboom et al., 2007), a limited number of studies make an explicit link between language, cultural differences and IKT in the context of international joint ventures or cross-border M\&As (Buckley et al., 2006; Vaara et al., 2012). Although the findings from these studies help to enhance our understanding of the impact of cultural contexts on IKT, they are constrained to the same organizational context where intra-firm KT takes place. Our findings show the interaction between language, cultural contexts and interfirm IKT in the presence of migrants helps to overcome language and cultural barriers and facilitate IKT. This aspect is particularly important in the cultural context where meaning is implicit and hard for outsiders to understand (Hall, 1976) and represents a challenge in knowledge exchanges. Our findings suggest that the concept of absorptive capacity should incorporate the linguistic competence and cultural competence of individuals when taking language and cultural context into account. Thus, we propose: 
Proposition 4: The accuracy and the efficacy of exchange of both explicit and tacit knowledge in inter-firm IKT can be improved by migrants with bilingual and bicultural competence when taking into account the language and cultural context.

\subsection{Contributions}

Our study advances the inter-firm IKT literature in three main ways. First, by taking a processual perspective, it delineates the nature and complexity of the process of inter-firm IKT in the language and cultural context. Specifically, we propose that the process of interfirm IKT is interactive and dynamic, involving back and forth movements. Each of three stages of the IKT process involves language and cultural interactions between knowledge sources and recipients. While the importance of attitudes and the willingness of knowledge sources and recipients in IKT have been mentioned in prior research (Gupta \& Govindarajan, 2000; Pérez-Nordtvedt et al., 2008; Szulanski, 1996), we move beyond this by linking the language and cultural context to various stages and the evolution of the IKT process. We find that language and culture are more than a communication tool and communication context. They affect the search for potential sources of knowledge, as well as the willingness, efficiency and effectiveness of IKT. Our findings enrich existing research on the process of inter-firm IKT by moving away from emphasis on the properties of knowledge and technical barriers to contextual factors (language and culture) in such a process.

Second, with a focus on the impact of migrants on inter-firm IKT, our study advances existing research by emphasizing how individuals with bilingual and bicultural competence help to overcome barriers to IKT. This aspect has been underexplored theoretically and empirically. Taking the unsocialized view of IKT, most quantitative studies treat the language and cultural context as given (Blalock \& Simon, 2009; Filatotchev et al., 2011; Gong \& Girma, 2008; Görg \& Strobl, 2005; Tian, 2007). In contrast, we provide new insights into the 
language and culture-dependent process of IKT and highlight individuals with a biculturalbilingual background acting as a new vehicle for bridging language and cultural gaps in interfirm IKT. Prior KT research focusing on organizational or group characteristics as the unit of analysis has overlooked the role of individuals. Such a focus may not fully reveal the challenges and difficulties in the process of IKT. Our study therefore bridges the gap between the organizational level and individual level by examining the interrelationship between the language and cultural context, the heterogeneity of individuals and the IKT process.

Third, we highlight the fact that the process of inter-firm IKT is multi-dimensional and is subject to double layers of language and cultural barriers. Language should not be separated or be considered in isolation, as a shared language alone does not guarantee an effective communication process. Language and culture co-evolve, and the interpretation and absorption of knowledge are contingent on the language and cultural context. The analysis of the process of IKT would be incomplete without considering these aspects simultaneously. Our findings indicate that language and cultural capabilities must work together for successful IKT.

\subsection{Theoretical Implications}

Theoretical implications can be derived from our research. First, scholars should pay more attention to the human element in IKT and go beyond merely a mechanical and unsocalized explanation of IKT. Despite the rapid process of globalization, language and cultural differences still have a profound impact on international knowledge flows. This aspect has been largely ignored in research based on quantitative analysis where the impact of language barriers and cultural barriers on IKT is 'invisible', and empirical measures have narrowly focused on the properties of knowledge and technical aspects of IKT. This constrains our understanding of the complexity of IKT. In particular, assuming knowledge 
flows are independent of language and cultural contexts overlooks the difficulties and challenges of IKT. In addition, an emerging trend of human mobility, such as migrants, has become an important aspect of globalization. Migrants with linguistic skills and a multicultural competence occupy the middle ground and have profound implications for organizations in their country-of-origin and adopted country. Research on IKT should pay particular attention to the heterogeneity of the workforce at the individual level, in addition to the organizational level, in order to capture the new trend of international migration and its impact. Examining the interrelationship between the language and cultural context and individuals with bilcultural-bilingual competence is an important advance in conceptualizing the IKT process.

\subsection{Managerial Relevance}

Our findings have important managerial implications. The topic of IKT has taken center stage in today's modern knowledge economy. Managers involved in IKT need to take a holistic approach in order to understand the process, from its evolution and its dynamics to the characteristics of the people involved in the process. First, inter-firm IKT is complex and starts long before the actual knowledge exchanges. Managers should be prepared from the very beginning to identify key contacts and develop quality relationships. Investing in these pre-knowledge-exchange stages paves the way for a successful IKT outcome. Our findings help managers gain a deep understanding of barriers and challenges in the IKT process, thus assisting them in the design of appropriate mechanisms to ensure the effective and efficient execution of IKT.

Second, given the needs of today's organizations in undertaking international business and the challenges arising from the international landscape, managers should proactively capitalize on bilingual and bicultural individuals' advantages to gain access to external 
knowledge. It is important to emphasize here that language and cultural competence needs to be simultaneously present in order to optimally facilitate IKT. Individuals with language and cultural competence can be motivated to contribute to boundary-spanning with regard to IKT by scanning and processing information efficiently and effectively and acting as agents of influence in relationship building. An appropriate strategy should be put in place which allows firms to benefit from the diversity of employees within their organization.

Third, it is widely recognized that networks facilitate access to external knowledge. Our findings suggest that utilizing individuals with bicultural and bilingual competence is an effective way to establish cross-border contacts, develop trust and enhance the quality of inter-organizational relationships. These individuals are invaluable. Though it is possible to recruit expatriates with language abilities, their lack of cultural knowledge could potentially be an issue in the IKT process. In contrast, highly skilled migrants can provide cultural sensitivity and empathy that are important in building networks and developing quality relationships with potential IKT participants.

Finally, the rise of emerging economies has shifted the center of gravity and Western firms need to pay attention to the diverse languages and cultures of these economies. Such awareness is important where there is a desire to gain external knowledge as IKT is deeply rooted in the language and cultural context. Although English has become the most commonly adopted business language in emerging economies, the proficiency as well as the willingness of people to communicate in English should not be taken for granted; language alone is not the key to successful IKT. Language interacts with culture. Recognizing that both language and cultural differences can pose extra challenges in IKT, MNC managers need to put in place appropriate mechanisms, such as assigning international migrants to IKT-related tasks to motivate IKT participants to share their knowledge more openly. 


\subsection{Limitations of the Study}

We acknowledge the limitations of the study and that further research is required. First, we considered how Chinese migrants facilitate inter-firm KT between Chinese and British firms. English is the most commonly used foreign language in China where it is taught in schools and universities. Further investigation into whether IKT differs when other foreign languages are used would be useful. Second, while we focused on Chinese migrants in the UK, research could be extended to other ethnic groups, e.g. Indian and Spanish in the US whose role in the development of their countries-of-origin has also been emphasized in the literature. Finally, we mainly focused on the language and cultural context of IKT, taking the differences of organizational structure and incentive schemes as given. Future studies should examine how inter-organizational relationships, and internal organizational structures and schemes interact with each other and jointly determine the scope and scale of IKT.

\section{Conclusion}

While prior studies have highlighted language and cultural barriers in intra-firm KT within MNCs, our knowledge of how language and cultural contexts affect the process of inter-firm IKT is limited. Taking a processusal perspective and the contextualized explanation approach, this study delineates the process of IKT across language and cultural boundaries. We examine how highly skilled migrants affect the IKT process based on multiple case studies of Chinese migrants working in the UK and involved in IKT with independent Chinese firms. Our findings reveal the dynamic process of IKT involving three main stages, and the migrants play an important role at each stage. Possessed with bilingual and bicultural competence, they act as a bridge between the sources and recipients of knowledge and facilitate the process of inter-firm IKT. By focusing on the role of individuals in the language and cultural context, we bring needed attention to the process of IKT. Our 
findings call for more research in this direction.

\section{Acknowledgements}

Financial support from the British Academy (SG101925) is gratefully acknowledged. The authors would also like to thank Professor David Thomas and other participants for their constructive comments on an earlier draft of this paper in the International Management Workshop at the AOM conference in Boston in August 2012.

\section{References}

Abbott, A. (1995). Sequence analysis: New methods for old ideas. Annual Review of Sociology, 21, 93-113.

Argote, L., McEvily, B., \& Reagans, R. (2003). An integrative framework and review of emerging themes. Management Science, 49, 571-582.

Argote, L. (1999). Organizational learning: Creating, retaining, and transferring knowledge. Norwell, MA: Kluwer.

Bell, M. P., \& Harrison, D. A. (1996). Using intra-national diversity for international assignments: A model of bicultural competence and expatriate adjustment. Human Resource Management Review, 6, 47-74.

Blalock, G., \& Simon, D. (2009). Do all firms benefit equally from downstream FDI? The moderating effect of local suppliers' capabilities on productivity gains. Journal of International Business Studies, 40, 1095-1112.

Brannen, M. Y. (2004). When mickey loses face: Recontextualization, semantic fit and the semiotics of foreignness. Academy of Management Review, 29, 593-616.

Brannen, M. Y., Garcia, D., \& Thomas, D. C. (2009). Biculturals as natural bridges for intercultural communication and collaboration. Paper presented at the International Workshop on Intercultural Collaboration, Palo Alto, CA.

Brannen, M.Y., \& Thomas, D. (2010). Bicultural individuals in organisations. International Journal of Cross Cultural Management, 10, 5-16.

Brown, J. S., \& Duguid, P. (2001). Knowledge and organization: A social-practice perspective. Organization Science, 12, 198-213.

Buckley, P., Carter, M., Clegg, J., \& Tan, H. (2005). Language and social knowledge in 
foreign-knowledge transfer to China. International Studies of Management \& Organization, 35, 47-65.

Buckley, P., Clegg, J., \& Tan, H. (2006). Cultural awareness in knowledge transfer to ChinaThe role of guanxi and mianzi. Journal of World Business, 41, 275-288.

Castellani, D., \& Zanfei, A. (2003). Technology gaps, absorptive capacity and the impact of inward investments on the productivity of European firms. Economics of Innovation and New Technology, 12, 555-576.

Chen, G., \& Starosta, W. (1998). Chinese conflict management and resolution: Overview and implications. Intercultural Communication Studies, VII, 1-17.

Davison, R. M., Ou, C. X. J., \& Martinsons, M. G. (2013). Information technology to support informal knowledge sharing. Information Systems Journal, 23, 89-109.

Docquier, F., \& Rapoport, H. (2011). Globalization, brain drain and development, IZA Discussion Paper No. 5590.

Duanmu, J. L., \& Fai, F. (2007). A processual analysis of knowledge transfer: From foreign MNCs to Chinese suppliers. International Business Review, 16, 449-473.

Easterby-Smith, M., Lyles, M. A., \& Tsang, E.W. K. (2008). Inter-organizational knowledge transfer: Current themes and future prospects. Journal of Management Studies, 45, 677690.

Eisenhardt, K. M. (1989). Building theories from case study research. Academy of Management Review, 14, 532-550.

Fai, F., \& Piekkari, R. (2003). Language issues in cross-border strategic alliances: An investigation of technological knowledge transfers. Twenty-ninth European International Business Academy (EIBA) annual conference proceedings. December, Copenhagen Business School, Denmark.

Filatotchev, I., Liu, X., Lu, J., \& Wright, M. (2011). Knowledge spillovers through human mobility across national borders: evidence from Zhongguancun Science Park in China. Research Policy, 40, 453-462.

Fitzsimmons, S. R. (2013). Multicultural employees: A framework for understanding how they contribute to organizations. Academy of Management Review, 38, 525-549.

Fontaine, R., \& Richardson, S. (2003). Cross-cultural research in Malaysia. Cross Cultural Management: An International Journal, 10, 75-89.

Foss, N. (1999). Capabilities, Confusion, and the costs of coordination: on some problems in recent research on inter-firm relations. Danish Research Unit for Industrial Dynamics, DRUID Working Paper 99-07. 
Friedman, R., \& Liu, W. (2009). Biculturalism in management: Leveraging the benefits of intrapersonal diversity. In R. S. Wyer, C. Y. Chiu \& Y. Y. Hong (Eds.), Understanding culture: Theory, research and application (pp. 343-360). New York: Psychology Press.

Gioia, D. A., Corley, K. G., \& Hamilton, A. L. (2013). Seeking qualitative rigor in inductive research: Notes on the Gioia methodology. Organizational Research Methods, 16, 1531.

Glaser, B. G., \& Strauss, A. L. (1967). The discovery of grounded theory: Strategies for qualitative research. New York: Aldine.

Gong, Y., \& Girma, S. (2008). FDI, linkages and the efficiency of state-owned enterprises in China. Journal of Development Studies, 4, 728-749.

Goodall, K., \& Roberts, J. (2003). Only connect: Teamwork in the multinational. Journal of World Business, 38, 150-164.

Görg. H., \& Strobl, E. (2005). Spillovers from foreign firms through worker mobility: an empirical investigation. Scandinavian Journal of Economics, 107, 693-709.

Gupta, A. K., \& Govindarajan, V. (2000). Knowledge flows within multinational corporations. Strategic Management Journal, 21, 473-496.

Hall, E. (1976). Beyond Culture. New York: Doubleday.

Harzing, A., Koster, K., \& Magner, U. (2011). Babel in business: The language barrier and its solutions in the HQ-subsidiary relationship. Journal of World Business, 46, 279-287.

Harzing, A. W., \& Feely, A. J. (2008). The language barrier and its implications for HQsubsidiary relationships. Cross Cultural Management: An International Journal, 15, 4961.

Henderson, J. K. (2005). Language diversity in international management teams. International Studies of Management and Organization, 35, 64-81.

Hogg, M. A., \& Terry, D. J. (2000). Social identity and self-categorization processes in organizational contexts. Academy of Management Review, 25, 121-140.

Hong, Y., Morris, M. W., Chiu, C.-Y., \& Benet-Martínez, V. (2000). Multicultural minds: A dynamic constructivist approach to culture and cognition. American Psychologist, 55, 709-720.

Hong, Y., Benet-Martinez, V., Chiu, C., \& Morris, M. (2003). Boundaries of cultural influence: Construct activation as a mechanism for cultural differences in social perception. Journal of Cross-Cultural Psychology, 34, 453- 464.

Hong, H. J. (2010). Bicultural competence and its impact on team effectiveness. International Journal of Cross Cultural Management, 10, 93-120. 
Huang, Q., Davison, R. M., \& Gu, J. (2011). The impact of trust, guanxi orientation and face on the intention of Chinese employees and managers to engage in peer-to-peer tacit and explicit knowledge sharing. Information Systems Journal, 21, 557-577.

Inkpen, A. C., \& Tsang, E. W. K. (2005). Social capital, networks, and knowledge transfer. Academy of Management Review, 30, 146-165.

Jonsen, K., Maznevski, M., \& Schneider, S. (2011). Diversity and its not so diverse literature: An international perspective. International Journal of Cross-cultural Management, 11, $35-62$.

Kirkbride, S., Tang, S., \& Westwood, I. (1991). Chinese conflict preferences and negotiation behavior: cultural and psychological influences. Organization Studies, 12, 365-386.

Kogut, B., \& Zander, U. (1992). Knowledge of the firm, combinative capabilities, and the replication of technology. Organization Science, 3, 383-397.

Langley, A. (2007). Process thinking in strategic organization. Strategic Organization, 5, 271-282.

Liu, X., \& Buck, T. (2007). Innovation performance and channels for international technology spillovers: Evidence from Chinese high-tech industries. Research Policy, 36, 355-366.

Lord, M. D., \& Ranft, A. L. (2000). Organizational learning about new international markets: exploring the internal transfer of local market knowledge. Journal of International Business Studies, 31, 573-589.

Makela, K., Kalla, H. K., \& Piekkari, R. (2007). Interpersonal similarity as a driver of knowledge sharing within multinational corporations. International Business Review, 16, $1-22$.

Miles, M., \& Huberman, A. (1984). Qualitative data analysis: A source book of new methods. Beverly Hills, CA: Sage.

Millington, A., Eberhardt, M., \& Wilkinson, B. (2006). Guanxi and supplier search mechanisms in China. Human Relations, 59, 505-532.

Monge, P. (1990). Theoretical and analytical issues in studying organizational processes. Organization Science, 1, 406-430.

Nooteboom, B., Van Haverbeke, W., Duysters, W., Gilsing, V., \& Ad van den Oord, A. (2007). Optimal cognitive distance and absorptive capacity. Research Policy, 36, 10161034.

Osland, J. S. (2000). The journey inward: Expatriate hero tales and paradoxes. Human Resource Management, 39, 227-238. 
Paik, Y. \& Sohn, J. D. (2004). Expatriate managers and MNCs ability to control international subsidiaries: the case of Japanese MNCs. Journal of World Business, 39, 61-71.

Peltokorpi, V. (2010). Intercultural communication in foreign subsidiaries: The influence of expatriates language and cultural competencies. Scandinavian Journal of Management, 26, 176-188.

Peltokorpi, V., \& Vaara, E. (2012). Language policies and practices in wholly owned foreign subsidiaries: A recontextualization perspective. Journal of International Business Studies, 43, 808-833.

Pérez-Nordtvedt, L., Kedia, B. L., Datta, D. K., \& Rasheed, A. A. (2008). Effectiveness and efficiency of cross-border knowledge transfer: An empirical examination. Journal of Management Studies, 45, 699-729.

Pettigrew, A. (1997). What is a processual analysis? Scandinavian Journal of Management, 13, 337-348.

Piekkari, R. (2006). Language effects in multinational corporations: A review from an international human resource management perspective. In G., Stahl, and I., Bjorkman, (Eds.), Handbook of Research in International Human Resource Management, Cheltenham: Edward Elgar.

Reagans, R., \& McEvily, B. (2003). Network structure and knowledge transfer: The effects of cohesion and range. Administrative Science Quarterly, 48, 240-267.

Roberts, J. (2000). From know-how to show how? Questioning the role of information and communication technologies in knowledge. Technology Analysis and Strategic Management, 12, 429-443.

Simonin, B. L. (2004). An empirical investigation of the process of knowledge transfer in international strategic alliances. Journal of International Business Studies, 35, 407-27.

Szulanski, G. (1996). Exploring internal stickiness: Impediments to the transfer of best practices within the firm. Strategic Management Journal, 17, 27-43.

Szulanski, G. (2000). The process of knowledge transfer: A diachronic analysis of stickiness. Organizational Behavior and Human Decision Processes, 82, 9-27.

Tadmor, C. T., \& Tetlock, P. E. (2006). Biculturalism: A model of the effects of secondculture exposure on acculturation and integrative complexity. Journal of Cross-Cultural Psychology, 37, 173-190.

Tadmor, C. T., Tetlock, P. E., \& Peng, K. (2009). Acculturation strategies and integrative complexity: The cognitive implications of biculturalism. Journal of Cross-Cultural Psychology, 40, 105-139. 
Tietze, S. (2008). International management and language. London: Routledge

Thomas, P. (2003). The recontextualization of management: A discourse-based approach to analyzing the development of management thinking. Journal of Management Studies, 40, 775-801.

Thomas, D. C., Stahl, G., Ravlin, E. C., Poelmans, S., Pekerti, A., Maznevski, M., \& Au, K. (2008). Cultural Intelligence: Domain and Assessment. International Journal of Cross Cultural Management, 8, 123-143.

Tian, X. (2007). Accounting for sources of FDI technology spillovers: Evidence from China. Journal of International Business Studies, 38, 147-159.

Tung, R. L. (1987). Enhancing success and managing failure. Academy of Management Executive, 1, 117-126.

United Nations (2010). International migration report 2009: A global assessment. Geneva: United Nations, Department of Economic and Social Affairs.

Vaara, E., Sarala, R., Stahl, G., \& Bjorkman, I. (2012). The impact of organizational and national cultural differences on social conflict and knowledge transfer in international acquisitions. Journal of Management Studies, 49, 1-27.

Vaara, E., Tienari, J., Piekkari, R., \& Santti, R. (2005). Language and the circuits of power in a merging multinational corporation. Journal of Management Studies, 42, 595-623.

Van de Ven, A. (2007). Engaged Scholarship: A Guide for Organizational and Social Research. Oxford: Oxford University Press.

Van Wijk, R., Jansen, J. P., \& Lyles, M. A. (2008). Inter- and intra-organizational knowledge transfer: a meta-analytic review and assessment of its antecedents and consequences. Journal of Management Studies, 45, 815-838.

Wang, P., Tong, T. W., \& Koh, C. P. (2004). An integrated model of knowledge transfer from MNC parent to China subsidiary. Journal of World Business, 39, 168-82.

Welch, D. E.,Welch, L. S., \& Piekkari, R. (2005). Speaking in tongues: The importance of language in international management processes. International Studies of Management and Organization, 35, 10-27.

Welch, C., Piekkari, R., Plakoyiannaki, E., \& Paavilainen-Mantymaki, E. (2011). Theorizing from case studies: Towards a pluralist future for international business research. Journal of International Business Studies, 42, 740-762.

Welch, D. E., \& Welch, L. S. (2008). The importance of language in international knowledge transfer. Management International Review, 48, 339-360.

World Migration, (2008). Highly skilled migration at 
http://www.iadb.org/intal/intalcdi/PE/2008/02382a04.pdf (accessed on 01 July 2013). Yin, R. K. (2009). Case study research, 4th Ed. Thousand Oaks, CA: Sage. 
Figure 1: Overview of data structure

$1^{\text {st }}$ Order Codes $2^{\text {nd }}$ Order Codes

Theoretical Categories

- Efficiently gather information about Chinese counterparts

- Understand the hierarchy \& social structure of Chinese firms

- Identify key decision makers

- Understand the importance of local officials

- Invite officials to social events and meetings

- Organize introductions to Chinese counterparts via local officials

- Understand what is appropriate to say/do in Chinese culture

- Communicate efficiently \& effectively in Chinese

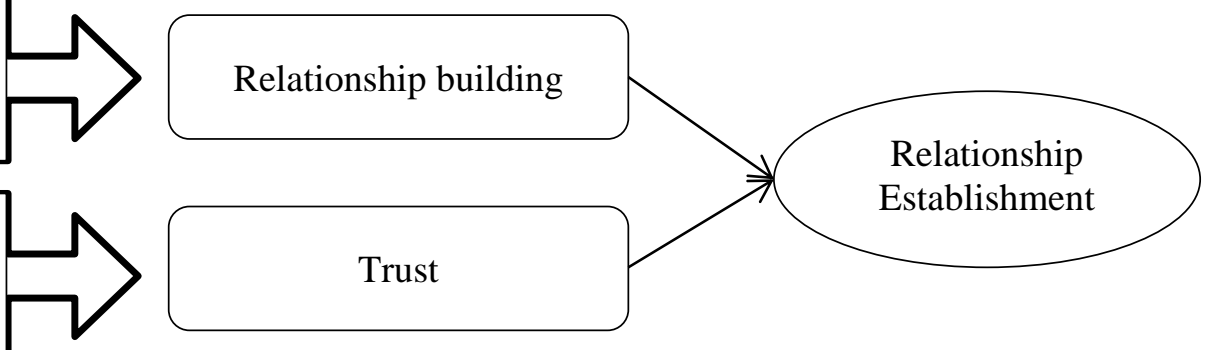

- Share in-group identity

- Provide reciprocal favors

- Develop personal relationships in addition to professional ones

- Ensure language efficiency in general communication

- Possess subject specific terminology

- Avoid English dialogues to save face for Chinese counterparts

- Possess language efficiency

- Understand cultural elements needed to decode knowledge correctly

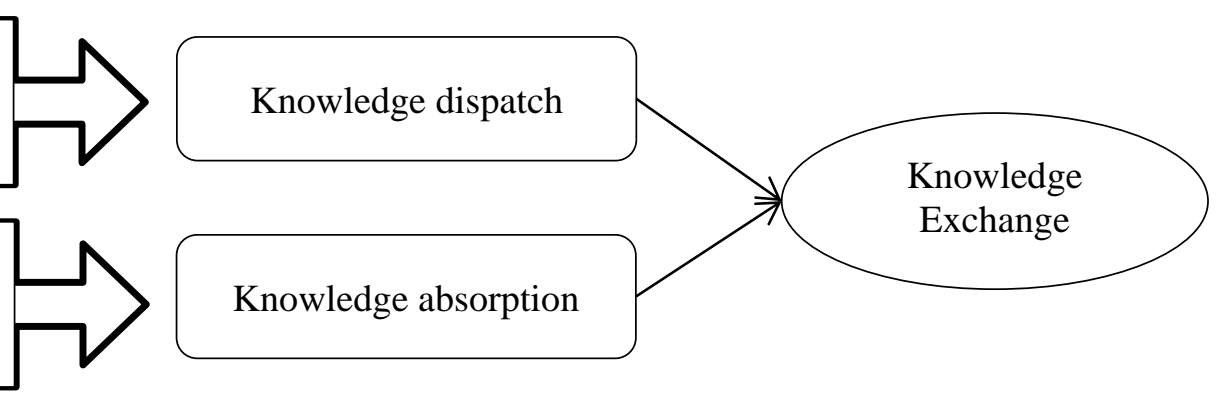


Figure 2: Migrants and the process of inter-firm IKT

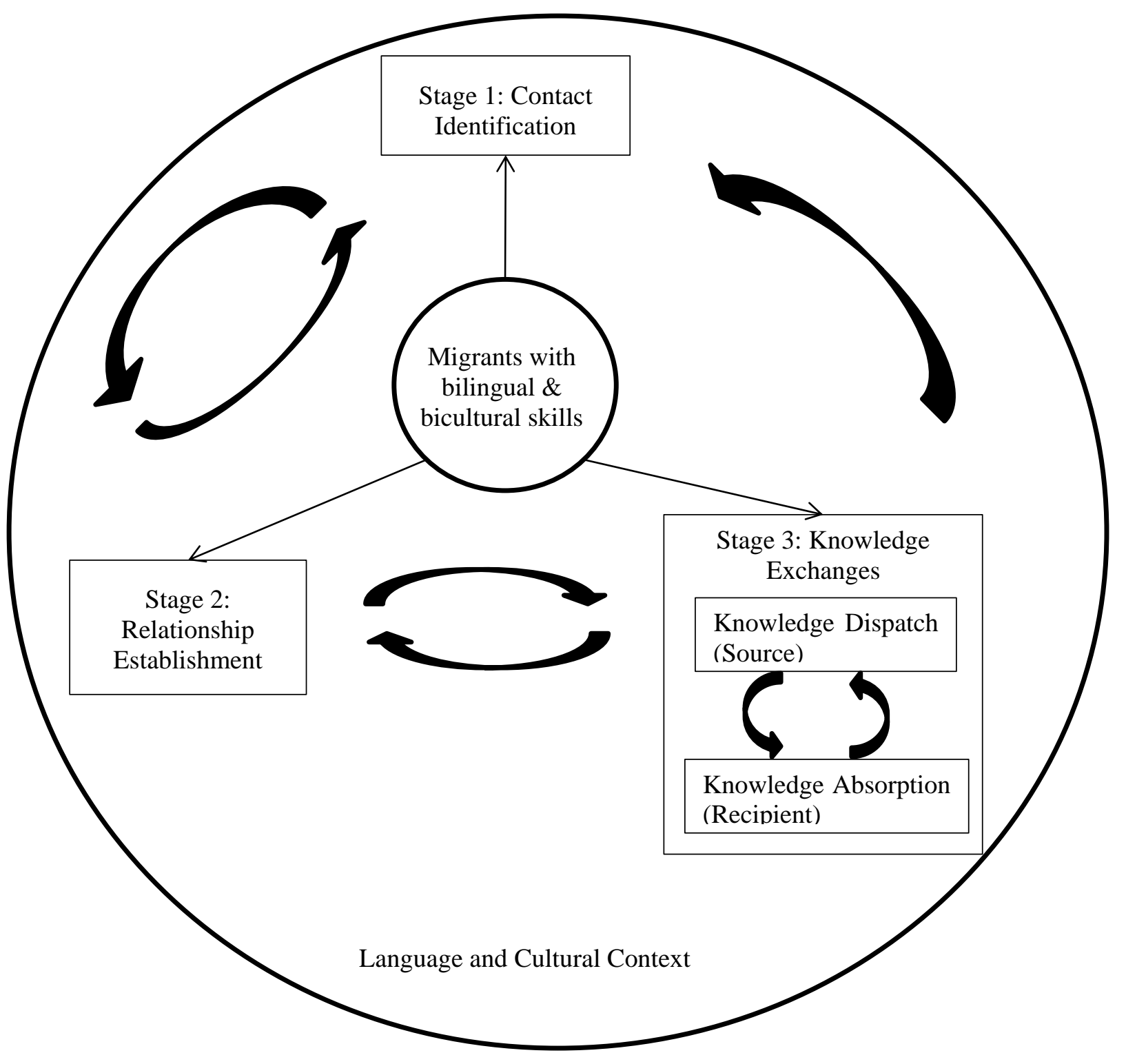


Table 1: UK case demographics

\begin{tabular}{|c|c|c|c|c|c|c|}
\hline Interviewee & Industry & Position & Education $^{a}$ & Interview Date & $\begin{array}{l}\text { Year } \\
\text { arrived } \\
\text { in UK }\end{array}$ & $\begin{array}{l}\text { Year started } \\
\text { working in UK }\end{array}$ \\
\hline $\mathrm{A}$ & IT & Project manager & $\mathrm{PhD}$ & $01 / 06 / 2011$ & 2005 & 2008 \\
\hline B & IT & Engineer & $\mathrm{PhD}$ & 02/06/2011 & 2004 & 2008 \\
\hline $\mathrm{C}$ & IT & Designer & MA & $12 / 06 / 2011$ & 2002 & 2007 \\
\hline $\mathrm{D}$ & IT & Managing director & $\mathrm{PhD} ; \mathrm{MBA}$ & 07/07/2011 & 1999 & 2005 \\
\hline $\mathrm{E}$ & IT & $\begin{array}{l}\text { Global marketing } \\
\text { manager }\end{array}$ & PhD; MBA & 12/07/2011 & 1997 & 2001 \\
\hline $\mathrm{F}$ & IT & Project manager & MSc; MBA & $29 / 07 / 2011$ & 2000 & 2005 \\
\hline $\mathrm{G}$ & IT & Project manager & $\mathrm{MSc}$ & 08/08/2011 & 2003 & 2004 \\
\hline $\mathrm{H}$ & IT & Engineer & MSc & $11 / 08 / 2011$ & 2003 & 2007 \\
\hline I & IT & Personal assistant & MA & $12 / 08 / 2011$ & 2004 & 2006 \\
\hline $\mathrm{J}$ & Pharmaceutical & Researcher & $\mathrm{PhD}$ & 18/08/2011 & 1996 & 2000 \\
\hline $\mathrm{K}$ & Pharmaceutical & Finance director & $\mathrm{PhD}$ & $12 / 09 / 2011$ & 1994 & 2000 \\
\hline $\mathrm{L}$ & Pharmaceutical & $\begin{array}{l}\text { China program } \\
\text { manager }\end{array}$ & $\mathrm{PhD}$ & 05/10/2011 & 1999 & 2004 \\
\hline M & Pharmaceutical & $\begin{array}{l}\text { China marketing } \\
\text { manager }\end{array}$ & $\mathrm{MSc}$ & $15 / 4 / 2013$ & 2003 & 2007 \\
\hline $\mathrm{N}$ & Pharmaceutical & Project manager & $\mathrm{PhD}$ & $18 / 4 / 2013$ & 2005 & 2009 \\
\hline
\end{tabular}

${ }^{a}$ : highest degree held by interviewees; MBA degree is presented wherever applicable. 
Table 2: Chinese case demographics

\begin{tabular}{lllll}
\hline Interviewee & Industry & Position & Education $^{\boldsymbol{a}}$ & Interview date $^{\text {In }}$ \\
\hline 1 & IT & Engineer & MSc & $01 / 07 / 2011$ \\
2 & IT & Market analyst & BA & $02 / 07 / 2011$ \\
3 & IT & Project manager & BSc & $09 / 07 / 2011$ \\
4 & Technology chief & PhD & $17 / 07 / 2011$ \\
& & & \\
5 & officer & Engineer & BEng & $25 / 07 / 2011$ \\
6 & IT & Project manager & MSc & $10 / 4 / 2013$ \\
7 & Pharmaceutical & CEO & PhD & $29 / 08 / 2011$ \\
8 & Pharmaceutical & Marketing manager & PhD & $10 / 10 / 2011$ \\
9 & Pharmaceutical & CEO & MSc & $19 / 10 / 2011$ \\
10 & Pharmaceutical & Manager & MSc & $20 / 4 / 2013$ \\
11 & Pharmaceutical & Market associate & BA & $25 / 4 / 2013$ \\
\hline $\boldsymbol{a}$ : highest degree held by interviewees; MBA degree is presented wherever applicable.
\end{tabular}

${ }^{a}$ : highest degree held by interviewees; MBA degree is presented wherever applicable. 